\title{
OESOPHAGUS
}

\section{Long term failure of endoscopic gastroplication (EndoCinch)}

\author{
I Schiefke, A Zabel-Langhennig, S Neumann, J Feisthammel, J Moessner, K Caca
}

Gut 2005;54:752-758. doi: 10.1136/gut.2004.058354

See end of article for authors' affiliations

.....................

Correspondence to:

Professor K Caca,

Department of Medicine II,

University of Leipzig,

Philipp-Rosenthal Str 27,

04103 Leipzig, Germany; caca@medizin.

uni-leipzig.de

Revised version received

1 December 2004

Accepted for publication

21 December 2004

\begin{abstract}
Introduction: Endoluminal gastroplication (EndoCinch; Bard) has been introduced as an endoscopic treatment option in gastro-oesophageal reflux disease (GORD) patients with promising short term results. However, little is known about the long term efficacy of endoscopic suturing. The aim of this study was to evaluate prospectively the long term outcome after EndoCinch.

Patients and methods: A total of 70 patients treated with EndoCinch at a single referral centre were studied prospectively. All patients were interviewed using a standardised questionnaire regarding their symptoms and medication prior to and 18 months after EndoCinch. In addition, follow up included endoscopy, 24 hour pH monitoring, and oesophageal manometry.

Results: The procedure was well tolerated without major short or long term complications. Eighteen months after EndoCinch, 56/70 patients (80\%) were considered treatment failures as their heartburn symptoms did not improve or proton pump inhibitor medication exceeded $50 \%$ of the initial dose. Endoscopy showed all sutures in situ in 12/70 (17\%) patients while no remaining sutures could be detected in 18/70 (26\%). In 54 and 50 patients examined, respectively, no significant changes in 24 hour $\mathrm{pH}$ monitoring (median pH $<4 / 24$ hours, $9.1 \% \vee 8.5 \% ; \mathrm{p}=0.82$ ) or lower oesophageal sphincter (LOS) pressure $(7.7 \vee$ $10.3 \mathrm{~mm} \mathrm{Hg} ; p=0.051$ ) were observed while median LOS length slightly increased ( 3.0 to $3.2 \mathrm{~cm}$; $\mathrm{p}<0.05$ ).

Conclusion: Endoscopic gastroplication (EndoCinch) is a safe and minimally invasive endoscopic treatment for GORD with reasonable short term results. In contrast, long term outcome is disappointing, probably due to suture loss in the majority of patients. Therefore, technical improvements to ensure suture durability are mandatory before endoscopic suturing can evolve as a therapeutic option for GORD treatment.
\end{abstract}

G astro-oesophageal reflux disease (GORD) is one of the most prevalent diseases in industrialised countries. Approximately $15-25 \%$ of adults, especially in Western countries, suffer from reflux symptoms, characterised mainly by heartburn and/or regurgitation. ${ }^{1}$ Longstanding oesophagitis may result in Barrett's metaplasia and oesophageal adenocarcinoma. ${ }^{2-4}$ Currently, antisecretory medication with proton pump inhibitors (PPIs) or antireflux surgery are the established options for GORD. PPIs are the therapeutic gold standard in acute, long term, or on demand therapy of GORD..$^{5-8}$ As PPIs do not restore the antireflux barrier but merely suppress acid secretion, lifelong tablet adherence is required in most cases.

Therefore, laparoscopic antireflux surgery is often proposed as a definitive alternative, especially in young patients to correct physiological and anatomical abnormalities. ${ }^{9} 10$ Surgery results in a positive long term outcome in $80-90 \%$ of patients. ${ }^{11}{ }^{12}$ However, antireflux surgery is associated with a significant morbidity and $0.3 \%$ mortality. ${ }^{913-16}$ Moreover, 10 years after antireflux surgery, $62 \%$ of patients have been reported to use acid suppressive therapy on a regular basis. ${ }^{17}$

In view of the limitations of PPIs and the potential risks of laparoscopic surgery, several endoscopic antireflux techniques were developed and may evolve as valuable third options. Four minimally invasive approaches have been approved recently by the FDA and introduced into clinical practice (that is, Stretta, Curon Medical Inc., Sunnyvale, California, USA; Enteryx, Boston Scientific, Natick, Massachusetts, USA; EndoCinch, Bard Endoscopic Technologies, Billerica, Massachusetts, USA; and Plicator, NDO Surgical Inc., Mansfield, Massachusetts, USA).

Among the endoluminal suturing devices, to date large scale testing has been done with the EndoCinch procedure. It was developed in the $1980 \mathrm{~s}^{18}$ and received FDA approval in
2000 for clinical use as an antireflux procedure. A multicentre study in 64 patients reported striking improvement in heartburn, regurgitation, and reduction in medication use six months after EndoCinch ${ }^{19}$ while 24 hour $\mathrm{pH}$ monitoring and manometry showed only modest changes. In another open label prospective trial, $62 \%$ of patients were off PPI medication (defined as $\leqslant 4$ doses/month). ${ }^{20}$ Additionally, the number of episodes of oesophageal acid exposure, heartburn symptoms, and regurgitation were also reduced 12 months post EndoCinch. ${ }^{20}$ However, loss of sutures or ineffective plications are a major technical problem that has not been addressed to date. As EndoCinch was shown to reduce transient lower oesophageal sphincter relaxations (tLOSR) and slightly increase lower oesophageal sphincter pressure (LOSP), the pressing question is the durability of the plications. ${ }^{21}$

Therefore, the aim of this single centre prospective study was to evaluate the long term efficacy of EndoCinch and durability of plications, 18 months after treatment.

\section{PATIENTS AND METHODS}

\section{Patients}

Between 2000 and 2002, 70 patients (26 women (38\%) and 44 men $(62 \%))$, median age 48 years (range $22-77$ ), with symptomatic GORD underwent endoscopic gastroplication using the Bard Interventional Endoscopic Suturing System (EndoCinch) at a single centre (University of Leipzig). All

Abbreviations: GORD, gastro-oesophageal reflux disease; PPIs, proton pump inhibitors; tLOSR, transient lower oesophageal sphincter relaxation; LOSP, lower oesophageal sphincter pressure; HBSS, heartburn severity scoring system; $\mathrm{H}_{2} \mathrm{RA}, \mathrm{H}_{2}$ receptor antagonist; DMJS, DeMeester-Johnson score; IQR, interquartile range; EAT, endoscopic antireflux therapy 
patients gave written informed consent and the protocol was approved by the local ethics committee.

Inclusion criteria were: symptoms of chronic heartburn and/or regurgitation ( $>2$ years); continuous PPI medication with at least partial symptom response (decrease in frequency and severity of symptoms); age $>18 /<80$ years; and pathological distal oesophageal acid exposure measured by 24 hour $\mathrm{pH}$ monitoring ( $\mathrm{pH}<4$ greater than $5.2 \%$ / 24 hours or a DeMeester-Johnson score $>14.7$ ). Exclusion criteria were: hiatal hernia $>3 \mathrm{~cm}$ in length; grade IV reflux oesophagitis; histological Barrett's mucosa; severe dysphagia; previous oesophageal surgery; specific motility disorders; or significant untreated medical conditions.

Patients required EndoCinch either because of incomplete response to antisecretory medication and/or refusal of lifelong medication with PPIs.

Patients meeting the inclusion and exclusion criteria were enrolled in the study and underwent the EndoCinch procedure.

\section{Clinical assessment}

Patients were evaluated by medical history, reason for EndoCinch (incomplete response to antisecretory medication or refusal of lifelong treatment with PPIs), age, sex, weight, body mass index, alcohol consumption (high alcohol consumption was defined as $>70 \mathrm{~g} /$ week), smoking status (smoker or non-smoker within six months before study inclusion), and use of acid suppressive therapy (expressed in equivalents of standard dose-that is, omeprazole $20 \mathrm{mg}$ / month) at baseline. Using a standardised GORD related questionnaire, all patients were interviewed before and at 3 , 6, 12, and 18 months after EndoCinch regarding reflux symptoms (that is, frequency and severity of heartburn, regurgitation, chest or epigastric abdominal pain, dysphagia, and respiratory symptoms after a 14 day period off acid suppressive medication). The frequency of symptoms was classified according to the modified DeMeester symptom scoring system. ${ }^{22} 23$

A heartburn severity scoring system (HBSS) was calculated as previously described, ${ }^{19}{ }^{24}$ and a detailed history of dosage and frequency of antisecretory medication over three months before EndoCinch and 3, 6, 12, and 18 months after the procedure was taken.

\section{Endoscopy and EndoCinch procedure}

Upper gastrointestinal endoscopy was performed in all patients using a high resolution videoendoscope (Olympus, Hamburg, Germany) before, 12, and 18 months post procedure. Initially, endoscopy was carried out to assess grade of oesophagitis and size of hiatal hernia if present. Grade of oesophagitis was graded according to the Savary-Miller classification. ${ }^{25}$ Follow up endoscopies assessed the integrity of plications, their position, and the grade of oesophagitis.

For EndoCinch, a metal guidewire with a spring tip was passed through the endoscope into the pylorus and the endoscope was removed. A polyvinyl dilator (54F) and overtube $(60 \mathrm{~F})$ were passed over the guidewire. The dilator and guidewire were removed and the overtube served as an conduit for subsequent instrument passage. Another gastroscope with the mounted sewing capsule was advanced to the level of the $\mathrm{z}$ line. A minimum of two plications were placed for each procedure. One or two of these plications were placed along the lesser curve, $1.5 \mathrm{~cm}$ and $0.5 \mathrm{~cm}$ below the $\mathrm{z}$ line. Stitches to form the plication were placed in a circumferential pattern. All patients were sedated with a combination of midazolam and propofol. The procedure was performed by two experienced endoscopists who received training in the use of the EndoCinch techniques on two
Table 1 Demographic data at baseline

\begin{tabular}{ll}
\hline Characteristic & All patients $(\mathbf{n}=70)$ \\
\hline Age (y) & $48.4(38.8-63.2)$ \\
Body mass index $\left(\mathrm{kg} / \mathrm{m}^{2}\right)$ & $25.4(23.4-28.3)$ \\
Sex (male) & $44(62.9)$ \\
Smoking status (non-smoker) & $59(84.3)$ \\
High alcohol consumption & $29(41.4)$ \\
\hline Values are median (intequartile range) or $\mathrm{n}(\%)$.
\end{tabular}

occasions and by practising on cadaver pig models on three separate occasions.

\section{Oesophageal 24 hour pH metry}

Ambulatory $\mathrm{pH}$ monitoring was performed for a minimum of 20 hours after a 14 day intermission of antisecretory medication (including histamine $\mathrm{H}_{2}$ receptor antagonists $\left(\mathrm{H}_{2} \mathrm{RA}\right)$, PPI, and prokinetic medication; Digitrapper, Medtronic Inc., Düsseldorf, Germany) at baseline and after 12 months of follow up. A dual pH antimony catheter (sensor distance $15 \mathrm{~cm}$; Medtronic Inc.) was used. The proximal sensor was passed transnasally and positioned $5 \mathrm{~cm}$ above the manometrically determined proximal border of the LOS.

Patients were asked to note meal times, periods of sleep, and changes in body position. The following standard parameters were analysed: DeMeester-Johnson score (DMJS), percentage of total time $\mathrm{pH}<4$, and number of periods $\mathrm{pH}$ $<4$. Criteria for normalisation in patients were: cumulative percentage time with oesophageal $\mathrm{pH}<4 / 24$ hours less than $5.2 \%$ and DeMeester and Johnson score ${ }^{26}<14.7$.

\section{Oesophageal manometry}

Oesophageal manometry, using the station pull through technique, ${ }^{27}$ was performed transnasally in the supine position after a overnight fasting period of 12 hours with an eight channel low resistance constant perfusion system (Medtronic Inc.), at baseline and after 12 months of follow up.

We used a catheter consisting of polyethylene with lateral openings placed at $5 \mathrm{~cm}$ intervals from the distal end of the catheter. Four sensors were arranged radially around the circumference at the tip of the catheter. Static pressure (LOSP), length, and relaxation of the sphincter as well as oesophageal body peristaltic amplitude and contraction pattern were analysed. LOS was considered incompetent if the resting pressure was below $6 \mathrm{~mm} \mathrm{Hg}$ and/or intraabdominal length was $<1 \mathrm{~cm}$. For measurement of tubular

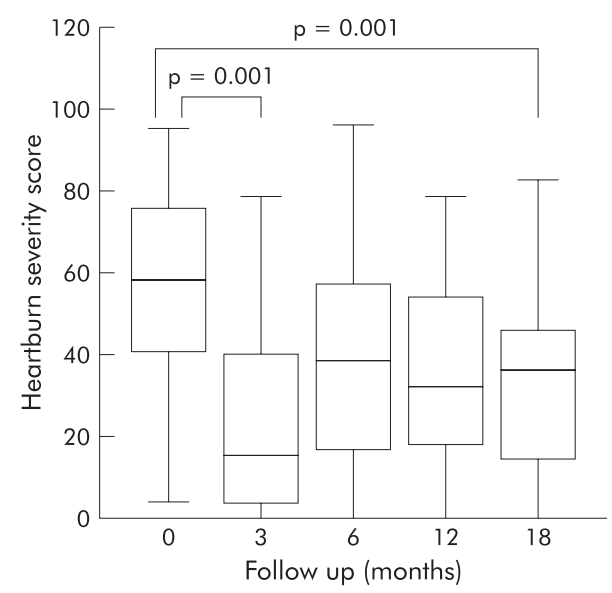

Figure 1 Heartburn severity score at baseline and at 3,6, 12, and 18 months of follow up. 
Table 2 Gastro-oesophageal reflux disease symptoms and proton pump inhibitor use at baseline and after 18 months of follow up

\begin{tabular}{lcccc}
\hline \multicolumn{5}{c}{ All patients $(\mathbf{n}=70)$} \\
\cline { 2 - 5 } Characteristic & Baseline & $\begin{array}{c}12 \text { month } \\
\text { follow up }\end{array}$ & $\begin{array}{c}18 \text { month } \\
\text { follow up }\end{array}$ & p Value \\
\hline HBSS & $58.2(41.0-76.3)$ & $32.2(17.9-54.4)$ & $36.8(14.4-46.1)$ & 0.001 \\
Dysphagia & $8(11.4)$ & $4(5.7)$ & $5(7.1)$ & \\
Regurgitation & $21(30.0)$ & $15(21.4)$ & $23(32.8)$ & \\
PPI use (equivalents of standard dose/months) & $7(10.0)$ & $4(5.7)$ & \\
None & $0(0)$ & $11(15.2)$ & $4(5.7)$ & \\
$1-10$ & $1(1.4)$ & $12(17.4)$ & $10(14.3)$ & \\
$11-20$ & $11(15.7)$ & $21(30.4)$ & $30(42.9)$ & \\
$21-30$ & $32(45.7)$ & $19(27.1)$ & $22(31.4)$ & \\
$>30$ & $26(37.1)$ & $0(0)$ & $0(0)$ & \\
$\mathrm{H}_{2} \mathrm{RA}$ use & $0(0)$ & & \\
\hline
\end{tabular}

Values are median (intequartile range) or $\mathrm{n}(\%)$.

HBSS, heartburn severity scoring system; PPI, proton pump inhibitor; $\mathrm{H}_{2} \mathrm{RA}, \mathrm{H}_{2}$ receptor antagonist.

oesophageal function, 10 wet swallows were evaluated. The definition of ineffective oesophageal motility included one or more of the following criteria: contraction amplitude in the distal oesophagus $<35 \mathrm{~mm} \mathrm{Hg}$, occurrence of simultaneous contraction, or interrupted contraction waves. Impaired oesophageal motility was diagnosed if $>30 \%$ of contractions were ineffective in 10 swallows of a $5 \mathrm{ml}$ bolus of water. ${ }^{27}$

\section{Statistical analysis}

All results were evaluated as mean (SD) or median (interquartile range (IQR)) for continuous variables, and frequency counts for categorical variables. Patients were assigned to the treatment failure group (non-responders) if HBSS at 18 months was not improved or the patient had a decrease in antisecretory medication doses to less than $50 \%$. Data were analysed with the Mann-Whitney rank sum test. The non-parametric Wilcoxon signed rank test was used to test the significance of $\mathrm{pH}$ monitoring, manometry data, PPI use, and HBSS symptom score before and after the procedure. A p value $<0.05$ was considered significant.

\section{RESULTS}

\section{Clinical assessment}

All patients who underwent the EndoCinch procedure between September 2000 and December 2002 at the University of Leipzig were evaluated for study participation. A total of 84 patients were screened. Of these, 70 patients entered the study: 10 patients lived in another state and were unable to participate in follow up visits and four patients declined the invasive follow up studies. The EndoCinch procedure was successfully completed in all patients. Patient data regarding age, sex, body mass index, smoking status,

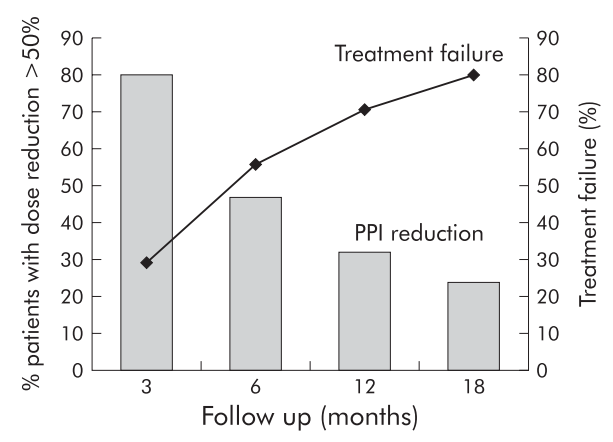

Figure 2 Proton pump inhibitor (PPI) use (percentage of patients with dose reduction $>50 \%$ ) and proportion of treatment failures (PPI reduction $<50 \%$ and/or no change in heartburn severity scoring system) after $3,6,12$, and 18 months of follow up.

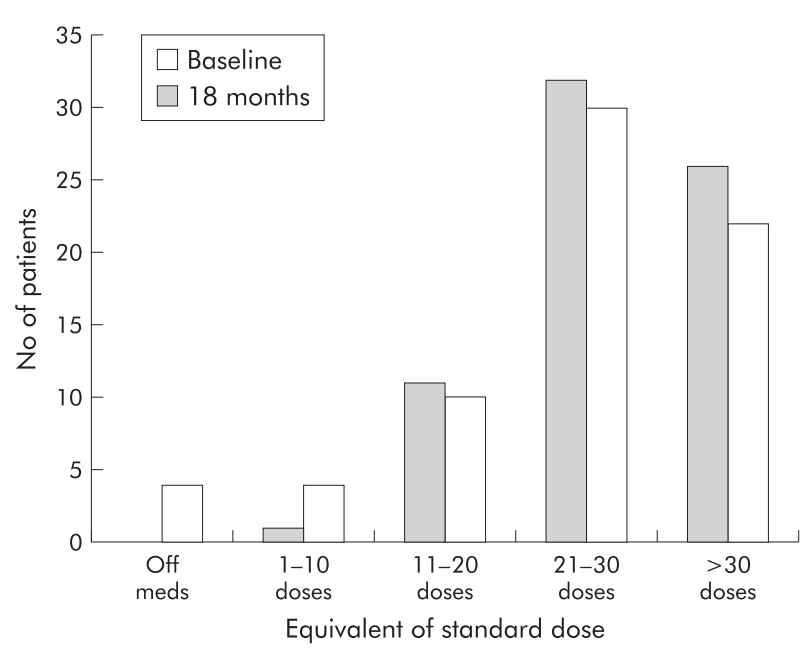

Figure 3 Proton pump inhibitor (PPI) use before EndoCinch (baseline) and 18 months after EndoCinch.

and alcohol ingestion prior to EndoCinch are shown in table 1. Assessment of the questionnaire and upper gastrointestinal endoscopy were performed as scheduled in all patients. Oesophageal manometry and 24 hour pH monitoring were available in 50 and 54 patients, respectively, included in the present trial.

HBSS score decreased after three months from 58.2 (41.0$76.3)$ to $15.4(3.5-40.3)$. The decline was most attributable to subjective lower visual analogue scale measurements. Although median HBSS increased in the follow up period (six months, 38.6 (17.2-56.6); 12 months, 35.6 (18.4-54.5)), a significant overall improvement was still found at 18 months after the procedure $(36.8(14.4-46.1) ; \mathrm{p}=0.001)$ (fig 1, table 2).

On entry, all patients were dependent on daily PPIs. Figure 2 shows the percentage of patients at each visit who had at least a $50 \%$ drop in medication doses. The proportion of patients with a significant drop in medication use declined rapidly during the first six months (three months: 56/70 $(80 \%)$; six months: $33 / 70(47 \%))$. During the following 12 months, the decline was more shallow (12 months: 23/70 (32\%); 18 months $17 / 70(24 \%)$ ). After 18 months, only 4/70 (6\%) patients were completely off PPIs (fig 3). Evolution of HBSS and PPI use correlated with sutures in situ after 18 months of follow up is summarised in fig 4 .

According to the combined end point at 18 months (decrease in medication doses $>50 \%$, patient satisfaction 

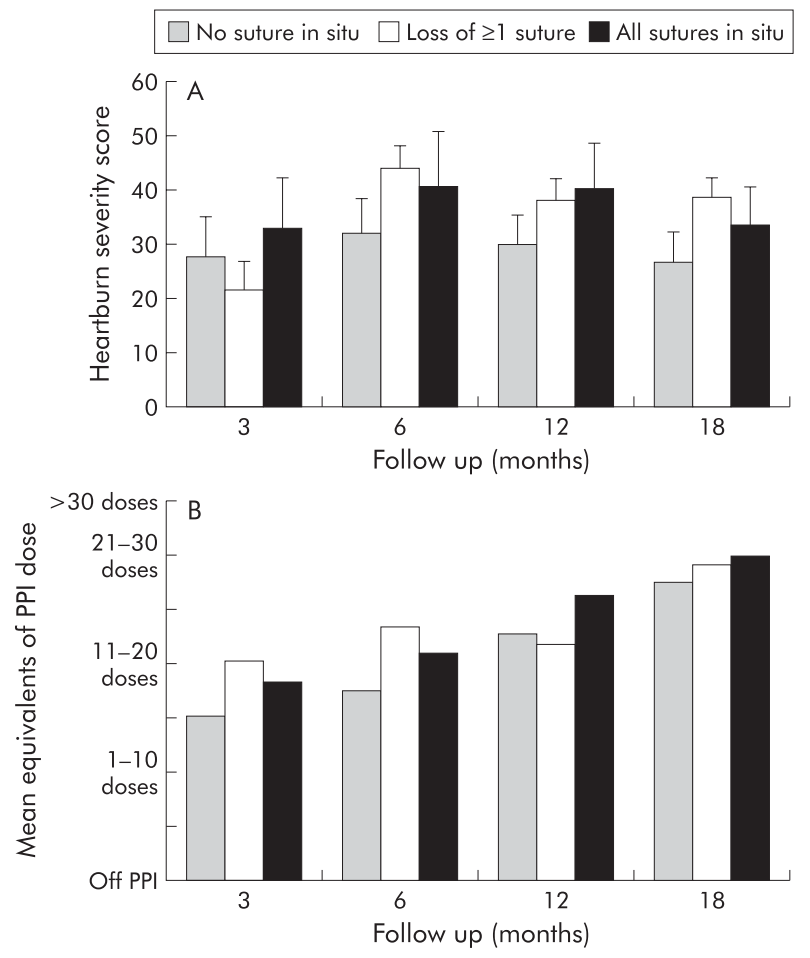

Figure 4 Post hoc analysis of heartburn severity scores $(A)$ and proton pump inhibitor (PPI) use (B) at 3, 6, 12, and 18 months after EndoCinch, correlated with loss of sutures or sutures in situ after 18 months of follow up.

and improvement in HBSS), 14/70 (20\%) were assigned to the "successfully treated group" (responders) whereas 56/70 $(80 \%)$ represented the "treatment failure group" (nonresponders). Thirty five of $46(76 \%)$ patients receiving EndoCinch because of incomplete response to PPIs were non-responders while $11 / 46(24 \%)$ responded to the endoscopic treatment. In contrast, $21 / 24(87 \%)$ patients who refused lifelong therapy did not respond to EndoCinch

whereas 3/24 (13\%) were still responders 18 months after therapy. These differences were not significant.

As judged by the endoscopist, only $4 / 173$ (2\%) sutures formed an effective plication (see fig 6A, B).

While the proportion of treatment responders declined during follow up, the proportion of patients dependent on PPIs increased continuously (fig 2).

\section{Endoscopy}

The EndoCinch procedure was finished in all patients as planned. All adverse events were mild and transient. Most frequently patients complained of retrosternal and pharyngeal pain $(58 / 70 ; 83 \%)$ and nausea/vomiting $(12 / 70 ; 17 \%)$ after the procedure. Symptoms resolved without treatment within one week in all patients. Eight of $70(11 \%)$ patients had a short bleeding episode which required endoscopic treatment during EndoCinch in two cases. No blood transfusions were required.

At evaluation for EndoCinch, endoscopy revealed nonerosive oesophagitis in 26/70 (37\%) patients, grade I in 26/70 (37\%), grade II in $16 / 70(23 \%)$, and grades in III-IV $2 / 70$ (3\%). Two patients initially showing grade III and IV oesophagitis were found to have grade II oesophagitis after four weeks of high dose PPIs prior to EndoCinch treatment (table 3). At control, 38/70 (54\%) patients still showed endoscopic evidence of oesophagitis 18 months after EndoCinch. Oesophagitis status remained unchanged in 40/ $70(57 \%)$ patients, was improved in 20/70 (29\%), and worsened in 10/70 (14\%). No significant change in oesophagitis severity was found $(\mathrm{p}=0.058)$.

Overall, a total of 173 sutures were placed: four sutures in three patients, three sutures in 27 patients, and two sutures in 40 patients were inserted. In $18 / 70(26 \%)$ patients, no suture was detected, in 30/70 (43\%) two had vanished, and in $24 / 70(34 \%)$ one suture was gone after 18 months of follow up (fig 5). Sutures were found in the same position as recorded at the time of implantation in 12/70 (17\%) patients only. Only $1 / 14(7 \%)$ of the responder subgroup had all sutures in situ while no remaining sutures were detected in $3 / 14(21 \%)$ patients. In addition, in $8 / 14(57 \%)$ patients only one, and in $2 / 14(14 \%)$ patients, two sutures were found. In

\begin{tabular}{|c|c|c|c|}
\hline \multirow[b]{2}{*}{ Characteristic } & \multicolumn{3}{|l|}{ Patients } \\
\hline & Baseline & Follow up & $\mathrm{p}$ Value \\
\hline \multicolumn{4}{|l|}{ At 12 months } \\
\hline 24 hour $\mathrm{pH}$ monitoring & $n=68$ & $\mathrm{n}=54$ & \\
\hline $\mathrm{pH}<4.0(\%)$ & $9.1(5.6-16.4)$ & $8.5(4.0-19.1)$ & 0.82 \\
\hline DeMeester score & $32.7(20.5-59.5)$ & $24.1(15.2-70.4)$ & 0.97 \\
\hline Oesophageal manometry & $\mathrm{n}=67$ & $\mathrm{n}=50$ & \\
\hline LOS pressure $(\mathrm{mm} \mathrm{Hg})$ & $7.7(5.0-11.8)$ & $10.3(6.2-13.2)$ & 0.051 \\
\hline LOS length $(\mathrm{cm})$ & $3.0(2.0-3.5)$ & $3.2(2.0-4.0)$ & $<0.05$ \\
\hline Non-specific motility disorders (\%) & $29(43.9)$ & $22(44.0)$ & \\
\hline Endoscopy & $n=70$ & $\mathrm{n}=70$ & \\
\hline \multicolumn{4}{|l|}{ Oesophagitis (\%) } \\
\hline Grade 0 & $26(37.1)$ & $25(35.7)$ & \\
\hline Grade I & $26(37.1)$ & $37(52.9)$ & \\
\hline Grade II & $16(22.9)$ & $6(8.6)$ & \\
\hline Grade III/IV & $2(2.9)$ & $2(2.9)$ & \\
\hline \multicolumn{4}{|l|}{ At 18 months } \\
\hline Endoscopy & $n=70$ & $n=70$ & \\
\hline \multicolumn{4}{|l|}{ Oesophagitis (\%) } \\
\hline Grade 0 & & $32(45.7)$ & \\
\hline Grade I & & $27(38.6)$ & \\
\hline Grade II & & $9(12.9)$ & \\
\hline Grade III/IV & & $2(2.9)$ & \\
\hline
\end{tabular}




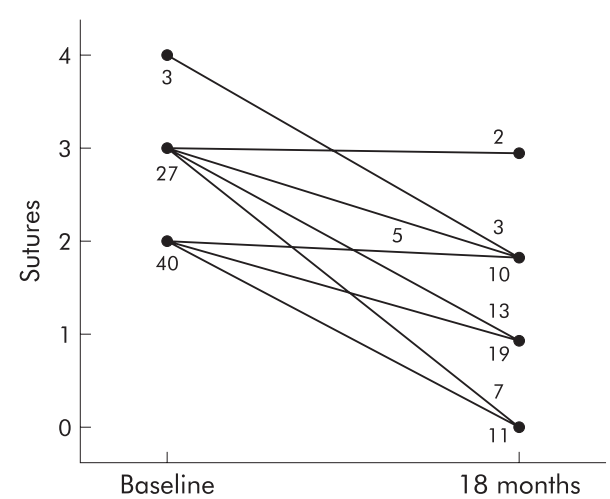

Figure 5 Sutures in situ at baseline (during EndoCinch) and after 18 months of follow up.

the non-responder group a similar pattern was detected: differences were not significant ( $1 / 56(2 \%)$ patients with all sutures in situ, 16/56 (29\%) with two sutures in situ, 24/56 $(43 \%)$ with one suture in situ, and $16 / 56$ (27\%) with no suture in situ).

\section{Oesophageal manometry}

In 50 patients examined, median LOS pressure increased from 7.7 (IQR 5.0-11.8) to $10.3 \mathrm{~mm} \mathrm{Hg}$ (IQR 6.0-13.9) at the 12 month follow up, but failed to reach statistical significance $(p=0.051)$. Median LOS length increased from 3.0 to $3.2 \mathrm{~cm}(\mathrm{p}<0.05)$ (table 3$)$.

No change in oesophageal motor function of the tubular oesophagus was observed between visits.

\section{4 hour pH monitoring}

Prior to EndoCinch, all patients had pathological reflux based on 24 hour pH monitoring as inclusion criteria. No significant reduction in distal oesophageal acid exposure, as measured by $\mathrm{pH}<4 / 24$ hours $(9.1 \% v 8.6 ; \mathrm{p}=0.82)$ or DMJS (32.7 $v$ 24.1; $\mathrm{p}=0.97$ ) was detected in 54 patients at the 12 months follow up (table 3 ).

Interestingly, 16/54 (28\%) patients reached normalisation of 24 hour $\mathrm{pH}$ monitoring. Three were able to discontinue PPIs completely.

\section{DISCUSSION}

A number of different endoscopic antireflux therapies (EATs), including EndoCinch, have developed rapidly in recent years. EndoCinch was cleared by the FDA in 2000 . Promising short term efficacy rates were published in recent years. ${ }^{19} 28$ However, there are some unanswered questions concerning durability, medication use, and patient satisfaction beyond one year.

In the present study, EndoCinch proved its safety profile. The procedure was well tolerated and no major complications requiring surgical intervention were encountered. All minor complications (bleeding 11\%) and discomforts (pharyngeal pain $83 \%$ ) were self limiting and had no long term adverse outcomes. In accordance with our findings, there are only limited reports on severe bleedings, perforations, or stenosis. ${ }^{29-33}$ Discomfort reported in this study was comparable with other published data with EATs. ${ }^{19}{ }^{34} 35$ However, patients should be informed that EATs are endoscopic surgery not simply endoscopy.

Our findings suggest that, at present, EndoCinch is not an endoscopic treatment option for long term management of GORD. After 18 months of follow up only $20 \%$ of patients were able to reduce or discontinue PPI medication.

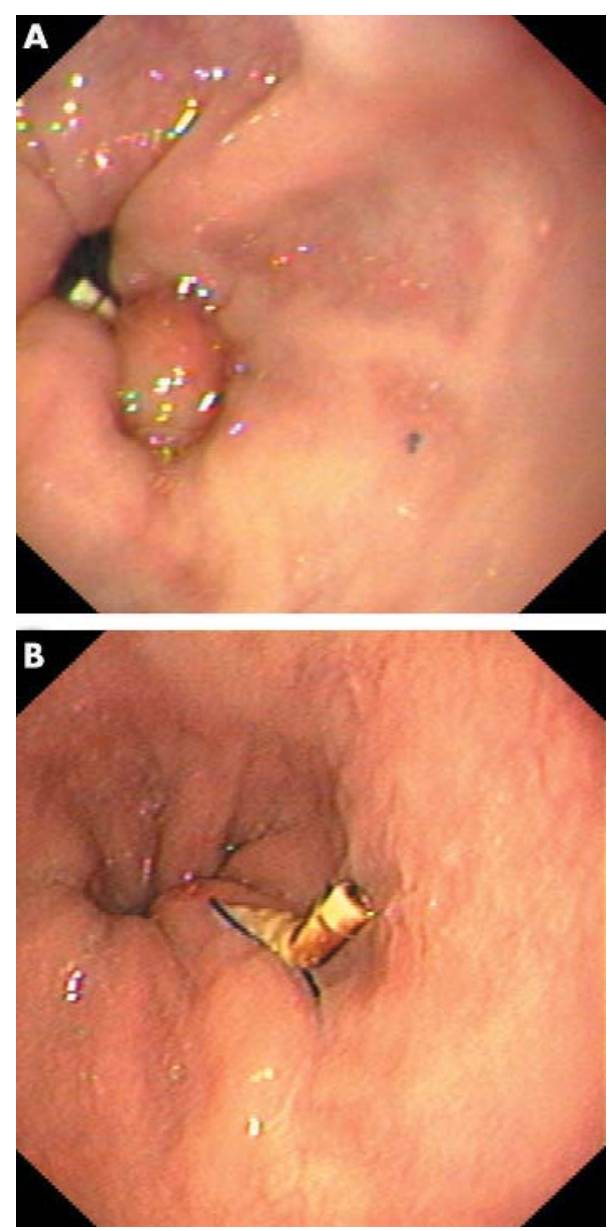

Figure 6 (A) Effective plication three months after EndoCinch (B) Plication in situ but ineffective due to partial tear after 18 months.

The vast majority of patients remain dependent on PPI, still reporting a reduction in subjective heartburn symptoms (HBSS). Other published studies regarding EndoCinch outcome reported an improvement in quality of life, reduction in heartburn symptom scores, time of $\mathrm{pH}<4 / 24$ hours, and DMJS, or PPI use in approximately two thirds of patients at 12 months. ${ }^{1920}$ These improvements were maintained throughout the whole of the study period without failure at the end of the one year follow up. In contrast, our efficacy rates declined from $71 \%$ at three months to $20 \%$ at 18 months. Moreover, $\mathrm{pH}<4 / 24$ hours, DMJS, or LOSP were not affected by the EndoCinch procedure. Remarkable was the reduction in subjective reflux symptom scores (HBSS) after EndoCinch $(\mathrm{p}=0.001)$. With respect to objective measurements ( $\mathrm{pH}<4 / 24$ hours) and the only slight reduction in PPI use, the high number of patients reporting a significant reduction in HBSS probably reflected a large "sham response rate" in this patient group.

A dilemma in treatment with endoscopic suturing devices is suture loss. A study with a 12 months follow up period reported only a slight loss of sutures, but previously addressed the problem. ${ }^{20}$ In 17/22 patients, plications were found in the same position as recorded at the time of the procedure, in three patients one of the two plications were found, and in two patients both plications had gone. ${ }^{20}$ In our study, more than $80 \%$ of patients had lost at least one suture and only $17 \%$ had all sutures in situ after 18 months, although all plications were done by an experienced endoscopist after an appropriate training period. According 
to the judgement of the endoscopist, only $2 \%$ of the formed plications were effective after 18 months.

One possible explanation could be derived from the histopathological analysis of endoluminal gastroplications in an animal model. Feitoza and colleagues ${ }^{36}$ found only shallow stitches with a flat scar, without fusion between folds, irrespective of suture penetration depth. All plications were gone after three days' survival time. As inflammation around the suture material and ischaemic areas are critical for the final outcome, further animal studies are required to assess the influence of penetration depth, knot strength, and suture length on durability of sutures.

In accordance with the observed loss of sutures only a slight, but not significant, improvement in DMJS and LOSP were observed. In addition, no changes in severity of reflux oesophagitis, a major goal in the treatment of GORD, were seen.

One putative mechanism of EndoCinch is alteration of LOS function. tLOSR was significantly reduced after the procedure. ${ }^{21}$ The influence of endoscopic therapy on LOSP is appraised differently in different studies. We observed a modest increase in LOSP $(7.7 \vee 10.3 \mathrm{~mm} \mathrm{Hg} ; \mathrm{p}=0.051)$. A similar modest increase in LOSP was reported in several other studies. ${ }^{19} 213738$ It remains questionable at best if such a small increase in LOSP is sufficient to reduce reflux significantly.

So far the effectiveness of EATs has been mainly assessed in short term trials (six or 12 months), without an appropriate control group (medical or surgical therapy). Sham controlled trials have been completed or are underway for all endoscopic treatments of GORD. ${ }^{39}{ }^{40}$ The first controlled trial published in 2003 included 64 patients with GORD, randomised to undergo the Stretta procedure or sham endoscopy. At six months, the Stretta procedure significantly reduced symptoms of GORD and improved quality of live compared with the sham treatment. However, the Stretta procedure did not decrease daily use of medication. ${ }^{39}$ Preliminary sham controlled data also exists for the EndoCinch procedure. ${ }^{40}$ In a single centre study, 34 patients were randomised to EndoCinch treatment or sham endoscopy. After three months of follow up, the EndoCinch procedure had reduced the frequency of GORD symptoms$61 \%$ in the EndoCinch group versus $31 \%$ in the sham groupillustrating a high placebo response rate. These data highlight the need for larger, longer, well designed trials to re-evaluate the efficacy of EATs.

Current therapy for GORD consists mainly of lifelong antisecretory medication (PPI) and laparoscopic antireflux surgery. Both strategies have disadvantages or potential hazards. . $^{5-12} 4142$ Therefore, exploring alternative endoscopic methods is warranted. However, the solution is not simply to use the available EATs. These devices have to be shown to be effective, durable, and safe in clinical trials before they can enter the mainstream of therapeutic options for patients with GORD.

In summary, EndoCinch was shown to be safe but not as efficient as expected after 18 months of follow up. In addition, the present study demonstrated that gross loss of plications was the putative mechanism for treatment failure in the majority of patients. Additionally, a decreasing placebo effect of EndoCinch over time is possible but can only be proven in a sham controlled study. EndoCinch clearly needs refinements in the device or in the procedure before it can be considered as a treatment option for GORD patients (for example, transmural suturing, ${ }^{43}$ helical transfer of sutures, ${ }^{44}$ or additional pretreatment of suture places by supplemental cautery $\left.{ }^{45}\right)$. These sobering data may help to intensify our efforts to develop improved endoluminal suturing devices with more durable and predictable results.
Authors' affiliations

I Schiefke, A Zabel-Langhennig, S Neumann, J Feisthammel, J Moessner, K Caca, Department of Medicine II, University of Leipzig, Leipzig, Germany

Conflict of interest: None declared.

\section{REFERENCES}

1 Nebel OT, Fornes MF, Castell DO. Symptomatic gastroesophageal reflux: incidence and precipitating factors. Am J Dig Dis 1976;21:953-6.

2 Klauser AG, Schindlbeck NE, Muller-Lissner SA. Symptoms in gastrooesophageal reflux disease. Lancet 1990;335:205-8.

3 Dimenas E, Glise H, Hallerback B, et al. Quality of life in patients with upper gastrointestinal symptoms. An improved evaluation of treatment regimens? Scand J Gastroenterol 1993;28:681-7.

4 Locke GR 3rd, Talley NJ, Fett SL, et al. revalence and clinical spectrum of gastroesophageal reflux: a population-based study in Olmsted County, Minnesota. Gastroenterology 1997;112:1448-56.

5 Vigneri S, Termini R, Leandro G, et al. A comparison of five maintenance therapies for reflux esophagitis. N Engl J Med 1995;333:1106-10.

6 Klinkenberg-Knol EC, Nelis F, Dent J, et al. Long-term omeprazole treatment in resistant gastroesophageal reflux disease: efficacy, safety, and influence on gastric mucosa. Gastroenterology 2000;118:661-9.

7 Kahrilas PJ, Falk GW, Johnson DA, et al. Esomeprazole improves healing and symptom resolution as compared with omeprazole in reflux oesophagitis patients: a randomized controlled trial. The Esomeprazole Study Investigators. Aliment Pharmacol Ther 2000;14:1249-58.

8 Vakil NB, Shaker R, Johnson DA, et al. The new proton pump inhibitor esomeprazole is effective as a maintenance therapy in GERD patients with healed erosive oesophagitis: a 6-month, randomized, double-blind, placebocontrolled study of efficacy and safety. Aliment Pharmacol Ther 2001;15:927-35

9 Lundell L. Laparoscopic fundoplication is the treatment of choice for gastrooesophageal reflux disease. Gut 2002;51:468-71.

10 Mattioli S, Lugaresi ML, Pierluigi $M$, et al. Indications for anti-reflux surgery in gastro-oesophageal reflux disease. Aliment Pharmacol Ther 2003;17(suppl 2):60-7.

11 DeMeester TR, Bonavina L, Albertucci M. Nissen fundoplication for gastroesophageal reflux disease. Evaluation of primary repair in 100 consecutive patients. Ann Surg 1986;204:9-20.

12 Lundell L, Abrahamsson $\mathrm{H}$, Ruth $\mathrm{M}$, et al. Long-term results of a prospective randomized comparison of total fundic wrap (Nissen-Rossetti) or semifundoplication (Toupet) for gastro-oesophageal reflux. Br J Surg 1996;83:830-5.

13 Gotley DC, Smithers BM, Rhodes M, et al. Laparoscopic Nissen fundoplication-200 consecutive cases. Gut 1996:38:487-91.

14 Bittner HB, Meyers WC, Brazer SR, et al. Laparoscopic Nissen fundoplication: operative results and short-term follow-up. Am J Surg 1994;167:193-8; discussion 199-200.

15 Perdikis G, Hinder RA, Lund RJ, et al. Laparoscopic Nissen fundoplication: where do we stand? Surg Laparosc Endosc 1997;7:17-21.

16 Lafullarde T, Watson DI, Jamieson GG, et al. Laparoscopic Nissen fundoplication: five-year results and beyond. Arch Surg 2001;136:180-4.

17 Spechler SJ, Lee E, Ahnen D, et al. Long-term outcome of medical and surgical therapies for gastroesophageal reflux disease: follow-up of a randomized controlled trial. JAMA 2001;285:2331-8.

18 Swain CP, Mills TN. An endoscopic sewing machine. Gastrointest Endosc 1986:32:36-8

19 Filipi CJ, Lehman GA, Rothstein RI, et al. Transoral, flexible endoscopic suturing for treatment of GERD: a multicenter trial. Gastrointest Endosc 2001;53:416-22

20 Mahmood Z, McMahon BP, Arfin Q, et al. Endocinch therapy for gastrooesophageal reflux disease: a one year prospective follow up. Gut 2003:52:34-9.

21 Tam WC, Holloway RH, Dent J, et al. Impact of endoscopic suturing of the gastroesophageal junction on lower esophageal sphincter function and gastroesophageal reflux in patients with reflux disease. Am J Gastroenterol 2004;99:195-202.

22 DeMeester TR, Johnson LF, Joseph GJ, et al. Patterns of gastroesophageal reflux in health and disease. Ann Surg 1976;184:459-70.

23 DeMeester TR, Johnson LF. The evaluation of objective measurements of gastroesophageal reflux and their contribution to patient management. Surg Clin North Am 1976;56:39-53.

24 Reading AE. Testing pain mechanism in persons with pain. In: Melzack Re, ed. Textbook of pain. New York, NY: Churchill Livingstone Inc, 1989:269-80.

25 Savary M, Miller G. The esophagus. In: Savary M, Miller G, eds. Handbook and atlas of endoscopy. Solothurn, Switzerland: Verlag Gassman, 1978: 119-295.

26 Johnson LF, DeMeester TR. Development of the 24-hour intraesophageal pH monitoring composite scoring system. J Clin Gastroenterol 1986;8(suppl 1):52-8.

27 Kahrilas PJ, Clouse RE, Hogan WJ. American Gastroenterological Association technical review on the clinical use of esophageal manometry. Gastroenterology 1994;107:1865-84.

28 Chadalavada R, Lin E, Swafford V, et al. Comparative results of endoluminal gastroplasty and laparoscopic antireflux surgery for the treatment of GERD. Surg Endosc 2004;18:261-5. 
29 Bittinger $M$, Messmann $\mathrm{H}$. New endoscopic therapies for gastroesophageal reflux disease. Z Gastroenterol 2003;41:921-8.

30 Caca K. Medikamentöse versus endoskopische Therapie der Refluxkrankheit Z Gastroenterol 2002;40:9-11.

31 Galmiche JP, Bruley des Varannes S. Endoluminal therapies for gastrooesophageal reflux disease. Lancet 2003;361:1119-21.

32 Abou-Rebyeh H, Hoepffner N, Rosch T, et al. Long-term failure of endoscopic suturing in the treatment of gastroesophageal reflux: a prospective follow-up study. Endoscopy 2005;37:213-16.

33 Tuebergen D, Rijcken E, Senninger N. Esophageal perforation as a complication of EndoCinch endoluminal gastroplication. Endoscopy 2004;36:663-5.

34 Johnson DA, Ganz R, Aisenberg J, et al. Endoscopic implantation of enteryx for treatment of GERD: 12-month results of a prospective, multicenter trial. Am J Gastroenterol 2003:98:1921-30.

35 Triadafilopoulos $\mathbf{G}$. Stretta: an effective, minimally invasive treatment for gastroesophageal reflux disease. Am J Med 2003;115(suppl 3A): 192-200S

36 Feitoza AB, Gostout CJ, Rajan E, et al. Understanding endolumina gastroplications: a histopathologic analysis of intraluminal suture plications. Gastrointest Endosc 2003;57:868-76.

37 Park P, Kjellin T, Kadirkamanthan S, et al. Results of endoscopic gastroplasty for gastroesophageal reflux disease. Gastrointest Endosc 2001;55:AB115.
38 Schiefke I, Soeder H, Zabel-Langhennig A, et al. Endoluminal gastroplication: what are the predictors of outcome? Scand J Gastroenterol 2004;39: 1296-303

39 Corley DA, Katz P, Wo JM, et al. Improvement of gastroesophageal reflux symptoms after radiofrequency energy: a randomized, sham-controlled trial. Gastroenterology 2003;125:668-76.

40 Rothstein RI, Hynes ML, Grove MR, et al. Endoscopic gastric plication (Endocinch) for GERD: a randomized, sham-controlled, blinded, single-center study. Gastrointest Endosc 2004:59:AB1111.

41 Chiba N, De Gara C, Wilkinson J, et al. Speed of healing and symptom relief in grade II to IV gastroesophageal reflux disease: a meta-analysis. Gastroenterology 1997;112:1798-810

42 DeVault KR, Castell DO. Updated guidelines for the diagnosis and treatment of gastroesophageal reflux disease. The Practice Parameters Committee of the American College of Gastroenterology. Am J Gastroenterol 1999:94:1434-42.

43 Chuttani R, Sud R, Sachdev G, et al. A novel endoscopic full-thickness plicator for the treatment of GERD: A pilot study. Gastrointest Endosc 2003;58:770-6.

44 Raiiman I, Walters R, Garza C, et al. Helical endoluminal gastroplication (ELGP) compared to standard ELGP in patients with gastroesophageal reflux disease (GERD). Gastrointest Endosc 2002;55:AB260.

45 Lehman G, Dunne D, Hieston K, et al. Suturing plication of cardia with endocinch device: Effect of supplemental cautery. A human prospective randomized trial. Gastrointest Endosc 2002;55:AB260.

\title{
EDITOR'S QUIZ: GI SNAPSHOT
}

\author{
Rare presentation of a common illness
}

Robin Spiller, Editor

\section{Clinical presentation}

A 40 year old previously healthy man presented as an emergency admission with a 10 day history of profuse watery diarrhoea up to 10 times per day but no blood in the stools. He also complained of mild headache, myalgia, and fever. He had vomiting and crampy abdominal pain two days prior to admission. He had last travelled on holiday to Sri Lanka three months prior to this admission, and at that time his daughter suffered from a self limiting diarrhoeal illness.

On examination he was pyrexial at $39^{\circ} \mathrm{C}$, pulse was 120 beats/min, and he was clinically dehydrated. He had a flat soft non-distended abdomen and left iliac fossa tenderness. There were no signs of peritonism. His haemoglobin level was $112 \mathrm{~g} / \mathrm{l}$. Platelet count was $1070 \times 10^{9}$, C reactive protein $289 \mathrm{mg} / \mathrm{l}$ (normal $<10$ ), and erythrocyte sedimentation rate $50 \mathrm{~mm} / \mathrm{h}$. Urea and electrolytes and liver tests were normal.

\section{Question}

An urgent unprepared colonoscopy was performed (fig 1). What is the diagnosis?

See page 763 for answer

This case is submitted by:

M M Hegde, N K Ahluwalia Department of Gastroenterology, Stepping Hill Hospital, Stockport, UK

Correspondence to: Dr N K Ahluwalia, Department of Gastroenterology, Stepping Hill Hospital, 33 Cedar House, Stockport SK2 7JE, UK navneet.ahluwalia@stockport-tr.nhs.uk

doi: 10.1136/gut.2004.048538

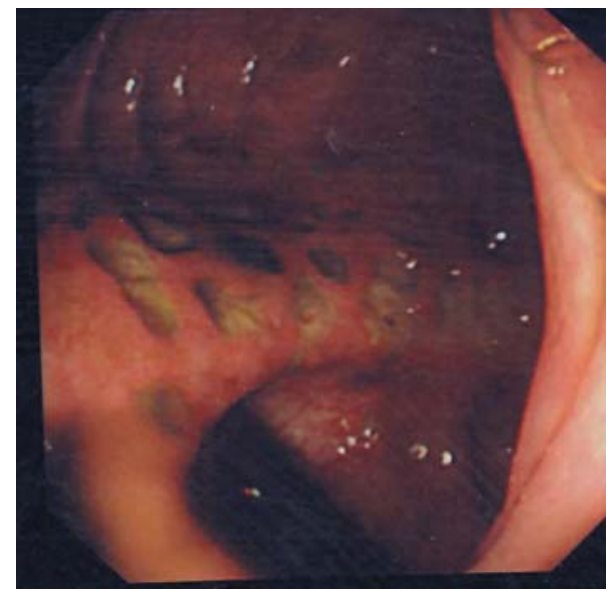

Figure 1 Caecum. 